\title{
Caracterização físico-química da água de um rio urbano amazônico, Capanema,
}

\author{
Pará, Brasil \\ Physical-chemical characterization of water from an amazon urban river, Capanema, Pará, Brazil \\ Caracterización físico-química del agua de un río urbano amazónico, Capanema, Pará, Brasil
}

Recebido: 05/11/2021 | Revisado: 16/11/2021 | Aceito: 25/11/2021 | Publicado: 06/12/2021

\author{
Eduardo Camurça da Silva \\ ORCID: https://orcid.org/0000-0002-8520-3741 \\ Universidade do Estado do Pará, Brasil \\ E-mail: duducs10@hotmail.com \\ Ana Lúcia Nunes Gutjahr \\ ORCID: https://orcid.org/0000-0001-7806-3069 \\ Universidade do Estado do Pará, Brasil \\ E-mail: melcam@uol.com.br \\ Carlos Elias de Souza Braga \\ ORCID: https://orcid.org/0000-0002-4621-8932 \\ Universidade do Estado do Pará, Brasil \\ E-mail: bragaelias@yahoo.com.br
}

\begin{abstract}
Resumo
A ocupação das margens dos rios urbanos impacta os ambientes aquáticos através do lançamento de efluentes e resíduos, remoção da vegetação ciliar e mudanças na configuração dos rios. Com isto, este trabalho objetivou realizar a caracterização físico-química do rio Ouricurí em Capanema, considerando a área da nascente, perímetro urbano e foz, observando a influência da sazonalidade e do crescimento urbano. Foram avaliados a Temperatura (T), pH, Oxigênio dissolvido (OD) e Condutividade elétrica (CE). A temperatura foi mais elevada na área urbana $\left(27.81^{\circ} \mathrm{C}\right)$ na estação menos chuvosa (EMC) e $29.26^{\circ} \mathrm{C}$ na estação chuvosa (EC), influenciada pela remoção da mata ciliar. A área da nascente apresentou pH ácido (N1 = 4.91 e 4.27 nas EMC e EC), influenciado pelo caráter lêntico dos pontos de coleta e o aporte de matéria orgânica, o pH foi básico na área urbana devido a concentração de efluentes domésticos no rio. $\mathrm{O}$ teor de OD foi maior na região da nascente, (N3 = 3,10 mg/L na EMC e 4,92 mg/L na EC), o parâmetro decresceu nas áreas urbana e foz, influenciado pela temperatura e a decomposição da matéria orgânica. A nascente apresentou a menor CE ( $\mathrm{N} 1=12,7 \mu \mathrm{S} \mathrm{cm}^{-1}$ e $25,3 \mu \mathrm{S} \mathrm{cm}{ }^{-1}$ para EMC e EC), e a foz níveis mais elevados, a CE é influenciada pelo aporte de efluentes não tratados. Verificou-se que a ocupação das margens do rio Ouricurí prejudica o meio ambiente aquático urbano, através de mudanças no meio físico, que alteram as variáveis físico-químicas indicativas da qualidade da água. Palavras chave: Qualidade da água; Crescimento urbano desordenado; Impacto ambiental.
\end{abstract}

\begin{abstract}
The occupation of the banks of urban rivers impacts aquatic environments through the release of effluents and residues, removal of riparian vegetation and changes in the configuration of rivers. With this, this work aimed to carry out the physical-chemical characterization of the Ouricuri river in Capanema, considering the spring area, urban perimeter and mouth, observing the influence of seasonality and urban growth. Temperature (T), pH, dissolved Oxygen (DO) and electrical conductivity (EC) were evaluated. The temperature was higher in the urban area $\left(27.81^{\circ} \mathrm{C}\right)$ in the less rainy season (EMC) and $29.26^{\circ} \mathrm{C}$ in the rainy season (EC), influenced by the removal of riparian vegetation. The spring area showed acid $\mathrm{pH}(\mathrm{N} 1=4.91$ and 4.27 in EMC and EC), influenced by the lentic character of the collection points and the contribution of organic matter, the $\mathrm{pH}$ was basic in the urban area due to the concentration of domestic effluents in the river. The content of DO was higher in the spring region, (N3 = 3.10 mg/L in EMC and $4.92 \mathrm{mg} / \mathrm{L}$ in EC), the parameter decreased in urban areas and mouth, influenced by temperature and decomposition of matter organic. The spring had the lowest EC ( $\mathrm{N} 1=12.7 \mu \mathrm{S} \mathrm{cm}^{-1}$ and $25.3 \mu \mathrm{S} \mathrm{cm}{ }^{-1}$ for EMC and EC), and the mouth of the highest levels, $\mathrm{EC}$ is influenced by the input of untreated effluents. It was found that the occupation of the banks of the Ouricuri river harms the urban aquatic environment, through changes in the physical environment, which alter the physicochemical variables indicative of water quality.
\end{abstract}

Keywords: Water quality; Disorderly urban growth; Environmental impact.

\section{Resumen}

La ocupación de las riberas de los ríos urbanos impacta los ambientes acuáticos a través de la liberación de efluentes y residuos, remoción de vegetación ribereña y cambios en la configuración de los ríos. Con ello, este trabajo tuvo como objetivo realizar la caracterización físico-química del río Ouricuri en Capanema, considerando la zona del manantial, 
perímetro urbano y desembocadura, observando la influencia de la estacionalidad y el crecimiento urbano. Se evaluaron la temperatura (T), el pH, el oxígeno disuelto (DO) y la conductividad eléctrica (CE). La temperatura fue mayor en el área urbana $\left(27,81^{\circ} \mathrm{C}\right)$ en la época menos lluviosa (EMC) y $29,26^{\circ} \mathrm{C}$ en la época lluviosa (CE), influenciada por la remoción de vegetación ribereña. El área de manantial presentó pH ácido (N1 = 4.91 y 4.27 en EMC y EC), influenciado por el carácter léntico de los puntos de captación y el aporte de materia orgánica, el pH fue básico en el área urbana debido a la concentración de efluentes domésticos en el río. El contenido de OD fue mayor en la región de primavera, (N3 = $3.10 \mathrm{mg} / \mathrm{L}$ en EMC y $4.92 \mathrm{mg} / \mathrm{L}$ en CE), el parámetro disminuyó en áreas urbanas y boca, influenciado por temperatura y descomposición de materia orgánica. El manantial tuvo la CE más baja $\left(\mathrm{N} 1=12,7 \mu \mathrm{S} \mathrm{cm-{ } ^ { 1 }}\right.$ y $25,3 \mu \mathrm{S}$ $\mathrm{cm}^{-1}$ para EMC y EC), y la boca de los niveles más altos, CE está influenciada por la entrada de efluentes no tratados. Se encontró que la ocupación de las riberas del río Ouricuri daña el medio acuático urbano, a través de cambios en el medio físico, que alteran las variables fisicoquímicas indicativas de la calidad del agua.

Palabras clave: Calidad del agua; Crecimiento urbano desordenado; Impacto ambiental.

\section{Introdução}

No Brasil, a busca pelo crescimento econômico e a ocupação intensa dos espaços naturais tem exaurido os recursos e reduzido o poder da natureza de se recompor. Essa situação se evidencia nas cidades, onde o meio físico, como suporte das atividades humanas, é mais requisitado, caracterizando o processo de ocupação e reorganização do território. À medida que a cidade cresce, são aterrados córregos e lagoas, cortadas encostas e ocupadas margens de rios levando a degradação progressiva de mananciais e áreas naturais (Lima, Lopes e Façanha, 2019).

O processo de urbanização desordenada determina impactos aos ambientes aquáticos, tanto pelas atividades econômicas quanto pela construção de vias de acesso e infraestrutura necessárias para a ocupação das populações humanas (Costa et al., 2021). Os problemas causados pelo crescimento urbano desordenado afetam os usos múltiplos da água em todas as regiões do Brasil, entre eles estão o déficit no saneamento básico, abastecimento municipal e a precária proteção dos mananciais (Andrade et al., 2016).

O aporte de poluentes nos rios em centros urbanos é constituído por cargas pontuais e difusas. As cargas pontuais tem sua origem, constituição e quantidade conhecidas ou podem ser estimadas a sua origem está associada ao lançamento indevido de efluentes industriais ou domésticos, devido à ausência de redes coletoras e de transporte de esgoto e os despejos clandestinos e irregulares. As cargas de origem difusa, ou poluição difusa, é constituída pelo material carreado no escoamento superficial durante as chuvas que chega aos corpos hídricos, causando impacto ao ambiente (Pereira et al., 2021).

O impacto ambiental conforme a resolução CONAMA 01/86 é definido como as alterações na biota, nas condições estéticas e sanitárias do meio ambiente e a qualidade dos recursos ambientais causadas por atividades sociais e econômicas (Brasil, 1986). Assim, para evitar danos aos ambientes aquáticos, a utilização da água superficial não deve impactar a conservação da diversidade biológica, os aspectos culturais e atividades recreativas, entre outros usos, com isso, surge a necessidade de monitorar os rios urbanos, a fim de tornar disponível informações que possibilitem a proposição de medidas adequadas ao manejo para manter a qualidade ecológica dos ambientes aquáticos (Ferreira et al., 2014).

O monitoramento das variáveis físico-químicas permite a identificação imediata de alterações nas propriedades da água, detecção precisa da variável modificada e a determinação das concentrações alteradas. No entanto, seu uso tem como desvantagem a descontinuidade temporal e espacial das amostras, fornecendo uma resposta momentânea de uma situação altamente dinâmica (Ceolin, Aguiar Junior, Moraes, 2017). Em termos ecológicos, o aporte de poluição na água de rios se manifesta através da variação dos níveis de oxigênio dissolvido (OD) e pH, causados pelo aumento do metabolismo de microrganismos envolvidos na depuração dos esgotos (Costa et al., 2021).

Mediante o exposto, o objetivo deste trabalho é verificar a relação das variações sazonais nos parâmetros físico-químicos temperatura, Oxigênio Dissolvido, pH e condutividade elétrica no rio Ouricurí em Capanema-Pa, associando aos impactos causados pelo crescimento urbano desordenado. 


\section{Metodologia}

\section{Área de estudo}

Capanema está localizado a $160 \mathrm{~km}$ da capital do estado, Belém, o município está inserido na Microrregião Bragantina e devido à posição geográfica é tido como a cidade polo da região. No contexto histórico do Nordeste Paraense, o crescimento do núcleo urbano de Capanema está associado à criação da Estrada de Ferro de Bragantina (E.F.B.) no início do século XX, seguido pela implantação das rodovias federais e estaduais na segunda metade do século XX (Ribeiro, 2019).

O clima do Município conforme a classificação Köppen é do tipo Am, um clima quente e úmido, dividido em duas estações: uma mais chuvosa, nos meses de dezembro a maio, e outra menos chuvosa, nos meses de junho a novembro. A precipitação pluviométrica média está em torno de $2.200 \mathrm{~mm}$ anuais e a umidade relativa do ar varia de $78 \%$ a $93 \%$. A temperatura média anual fica em torno de $26^{\circ} \mathrm{C}$, com máximas variando de $29^{\circ} \mathrm{C}$ a $31^{\circ} \mathrm{C}$ (Fapespa, 2014).

O rio Ouricurí, o objeto deste estudo, é o mais importante curso hídrico do município, considerando os rios presentes na área urbana. Este rio nasce ao nordeste da cidade, em área rural, cercado por fazendas e uma pequena vila. Também, passa por todo o centro comercial, percorrendo uma extensão aproximada de $9 \mathrm{~km}$, até desembocar no rio Capanema, que é afluente da margem esquerda do rio Peixe-boi. Apesar da proximidade ao núcleo urbano de Capanema, a foz do Ouricurí está localiza em uma fazenda, no município de Peixe boi, a cerca de 1 km da margem direita da PA-242.

\section{Delineamento amostral}

A pesquisa de campo de caráter exploratório seguiu o percurso que o rio Ouricuri faz dentro do município de Capanema, assim o objeto de estudo desta pesquisa foi seguimentado em três áreas (Nascente, Urbana e Foz), baseado na metodologia adotada por Silva, Everton e Melo (2016), com a finalidade de avaliar a influência do crescimento urbano desordenado sobre os parâmetros físico-químicos. A escolha dos parâmetros foi subsidiada conforme proposto por Couceiro (2009), assim foram mensurados os valores para a Temperatura (T), Oxigênio Dissolvido (OD), Potencial Hidrogeniônico (pH) e Condutividade elétrica (CE), associando estas a influência da sazonalidade na condição físico-química da água, para isso, as coletas foram realizadas nas estações menos chuvosa (novembro de 2020) e chuvosa (abril de 2021).

Os parâmetros físico-químicos foram mensurados em nove pontos distintos, sendo três pontos para cada área avaliada (Figura 1). Cada ponto foi constituído por três réplicas (margem esquerda, direita e leito) seguindo o curso do rio, para isso, foi utilizada uma sonda multiparâmetros (Hanna - HI9829), considerando-se para este estudo a média dos valores obtidos nas réplicas coletadas em cada ponto. 
Figura 1: Localização dos pontos de coleta no rio Ouricurí em Capanema-Pa.

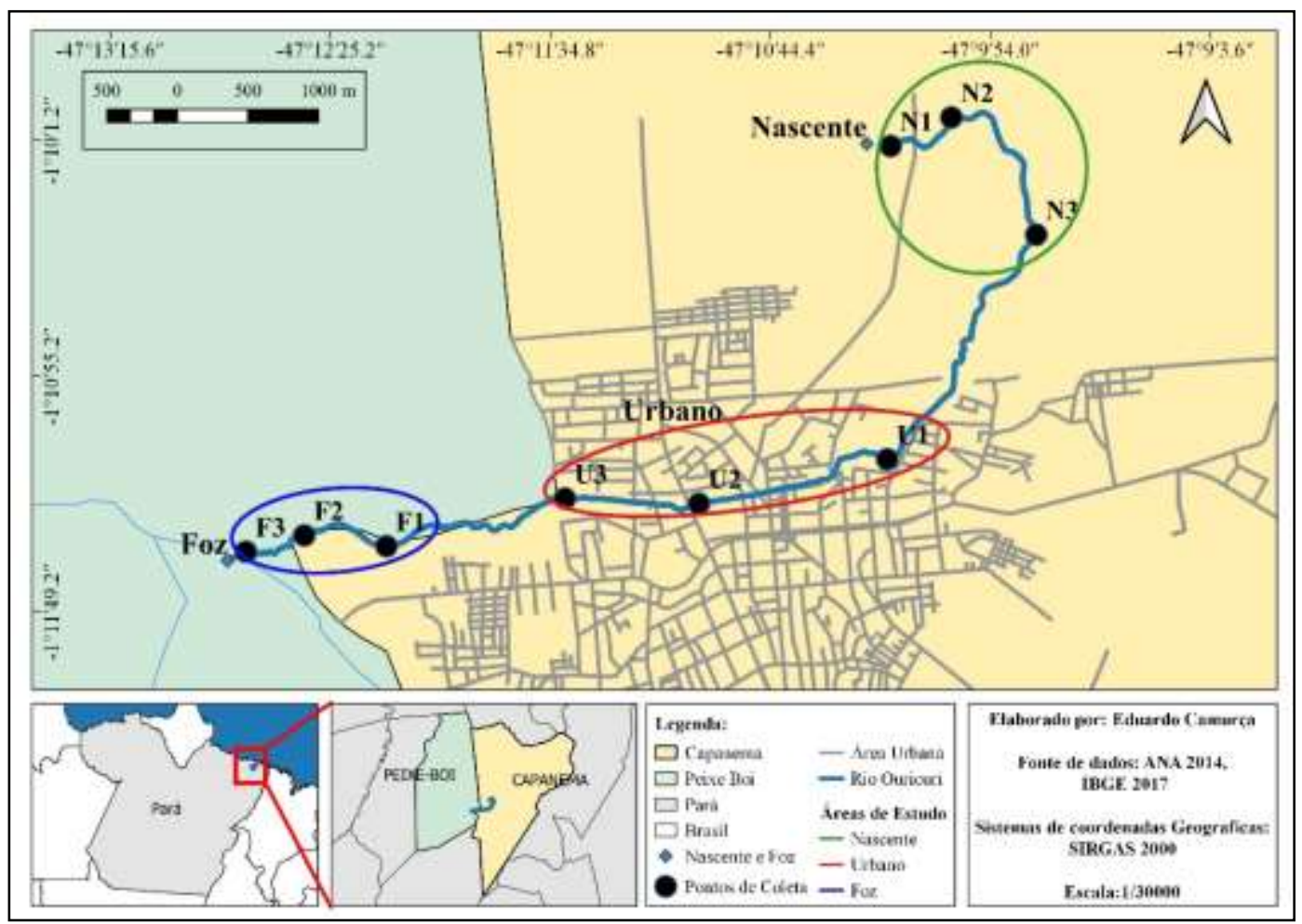

Fonte: Autores (2021).

\section{Caracterização das áreas de avaliação}

$\mathrm{Na}$ área da nascente, o ponto (N1) está circundado por fazendas e uma vila, a vegetação ciliar presente já se encontra bastante afetada pela presença humana, o ponto em que a coleta foi realizada tem características de ambiente lêntico, o qual forma uma lagoa que concentra a água proveniente da nascente, e é um provável local utilizado para a dessedentação de animais. O segundo ponto da área da nascente (N2), também possui características de ambiente lêntico, no entanto a origem se deve a atividade humana, pois se trata de uma depressão escavada no leito do rio, com vegetação circundante, em sua maioria rasteira, formada por gramíneas, e que sofreu uma queimada recente na estação menos chuvosa. O ponto (N3) estava localizado na saída de uma área de floresta, a profundidade era de aproximadamente $0,6 \mathrm{~m}$, sendo a área do entorno mais plana que na estação chuvosa, devido o nível da água, se eleva formando um charco.

$\mathrm{Na}$ área urbana a vegetação dos três pontos já se encontra modificada em função da ocupação de suas margens, em U1 a vegetação da margem direita do rio Ouricurí deu lugar a residências que direcionam os efluentes gerados para o rio, neste mesmo ponto há o encontro de outro curso hídrico contribuinte do rio Ouricurí. Em U2 o principal problema é causado pelas descargas de esgoto voltadas diretamente para o leito do rio, além do eventual descarte de resíduos sólidos, e a proximidade com as vias de circulação. Em U3 os principais problemas observados foram a presença de animais de grande porte, o descarte de resíduos sólidos, a falta de vegetação ciliar e a dragagem do leito. U3 está sob a influência de uma avenida importante para o município de Capanema, que liga a BR-316 a PA-124.

$\mathrm{Na}$ área da foz, o ponto F1 funciona como um filtro impedindo a passagem de resíduos sólidos e parte dos poluentes para os demais pontos. Na estação menos chuvosa havia um banco de macrófitas que barrava a passagem desses poluentes e servia de substrato para a fixação de alguns táxons de macroinvertebrados. No entanto este banco de macrófitas foi removido em função da chegada da estação chuvosa. Em F2 o rio se torna mais lago e com as macrófitas fixas ao leito, constituindo uma área pantanosa. O ponto F3 é uma área aberta com vegetação fixa ao leito do rio, a qual apresenta variação do nível da água e força da corrente na estação chuvosa (Figura 2). 
Figura 2: Áreas dos pontos em que foram realizadas as coletas das amostras, N1, N2 e N3 = Área da Nascente; U1, U2 e U3 = Área Urbana; F1, F2 e F3 = Área da Foz.
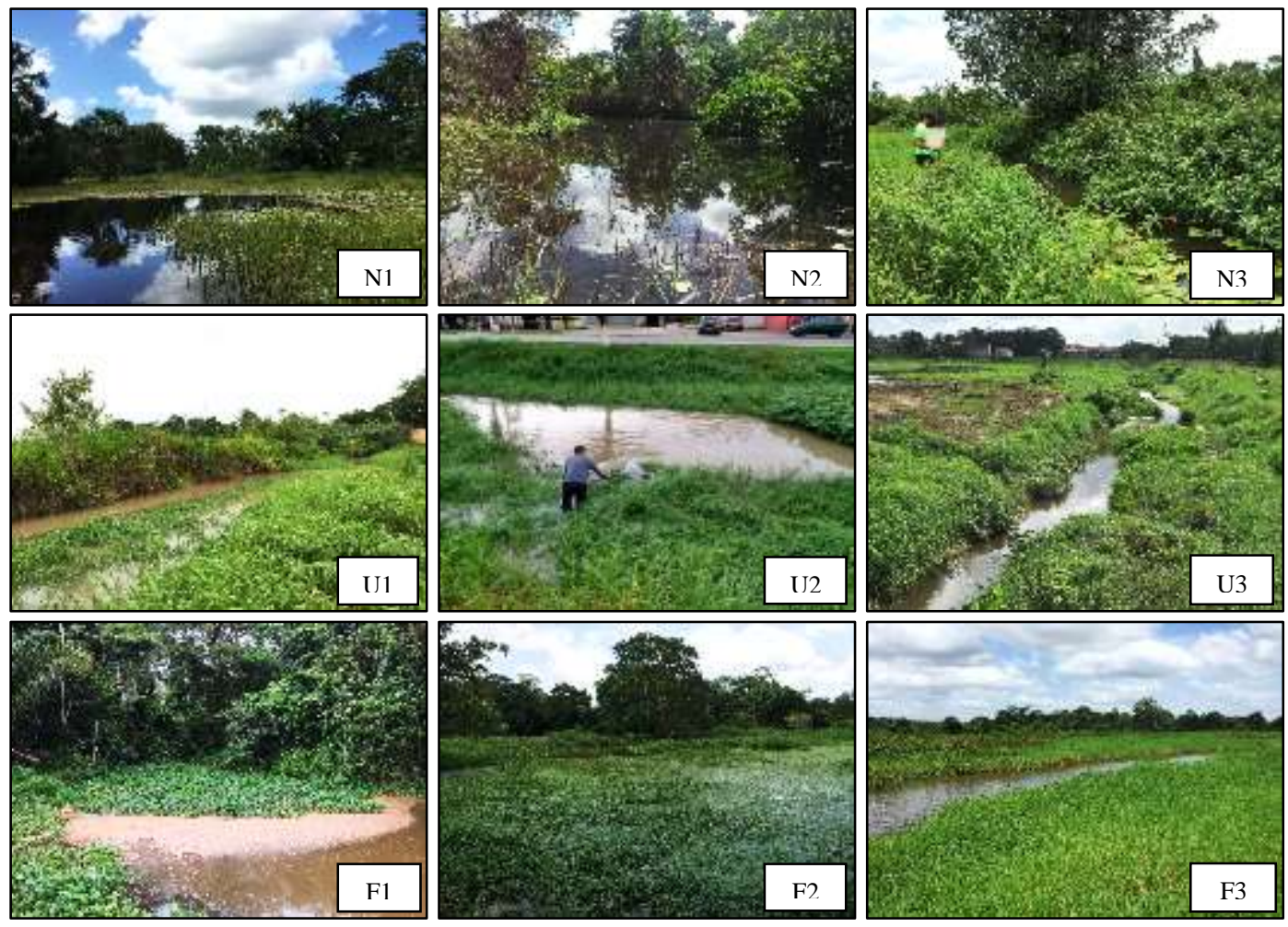

Fonte: Autores (2021).

\section{Análise de dados}

Os dados foram analisados através de análise descritiva de tabelas, por interposição de gráficos e Análise de Variância (ANOVA), com nível de significância de $\alpha=0,05$, para constatação da diferença entre os parâmetros físico-químicos (Temperatura, Oxigênio Dissolvido, pH e Condutividade elétrica) nos ambientes (Nascente, Urbano e Foz) amostrados, para isso, utilizou-se o pacote estatístico SYSTAT 11. Também, para verificar o nível de importância das variáveis físico-químicas (Temperatura, Oxigênio Dissolvido, pH e Condutividade elétrica) e suas relações com os diferentes ambientes (Nascente, Urbano e Foz) foi realizada uma Análise de Componentes Principais (ACP), através do programa PAST 3.

\section{Resultados e Discussão}

Durante o período de Amostragem verificou-se através da análise de componentes principais (PCA) que os fatores abióticos (Temperatura $=0,93 ;$ Oxigênio Dissolvido $=-0,74 ; \mathrm{pH}=0,84$ e Condutividade elétrica $=0,96)$ apresentam grande importância (variância explicada $=84,64 \%$ ) nos ambientes analisados no Rio Ouricuri, constatando-se que a Nascente está fortemente relacionada com o Oxigênio Dissolvido, o Ambiente Urbano do Rio com a Temperatura e o pH e a Foz com a Condutividade (Figura 3). 
Figura 3: Análise de Componentes Principais indicando o nível de importância das variáveis físico-químicas (Temperatura, Oxigênio Dissolvido, pH e Condutividade elétrica) e suas relações com os diferentes ambientes (Nascente, Urbano e Foz), no Rio Ouricuri, Capanema, Pará.

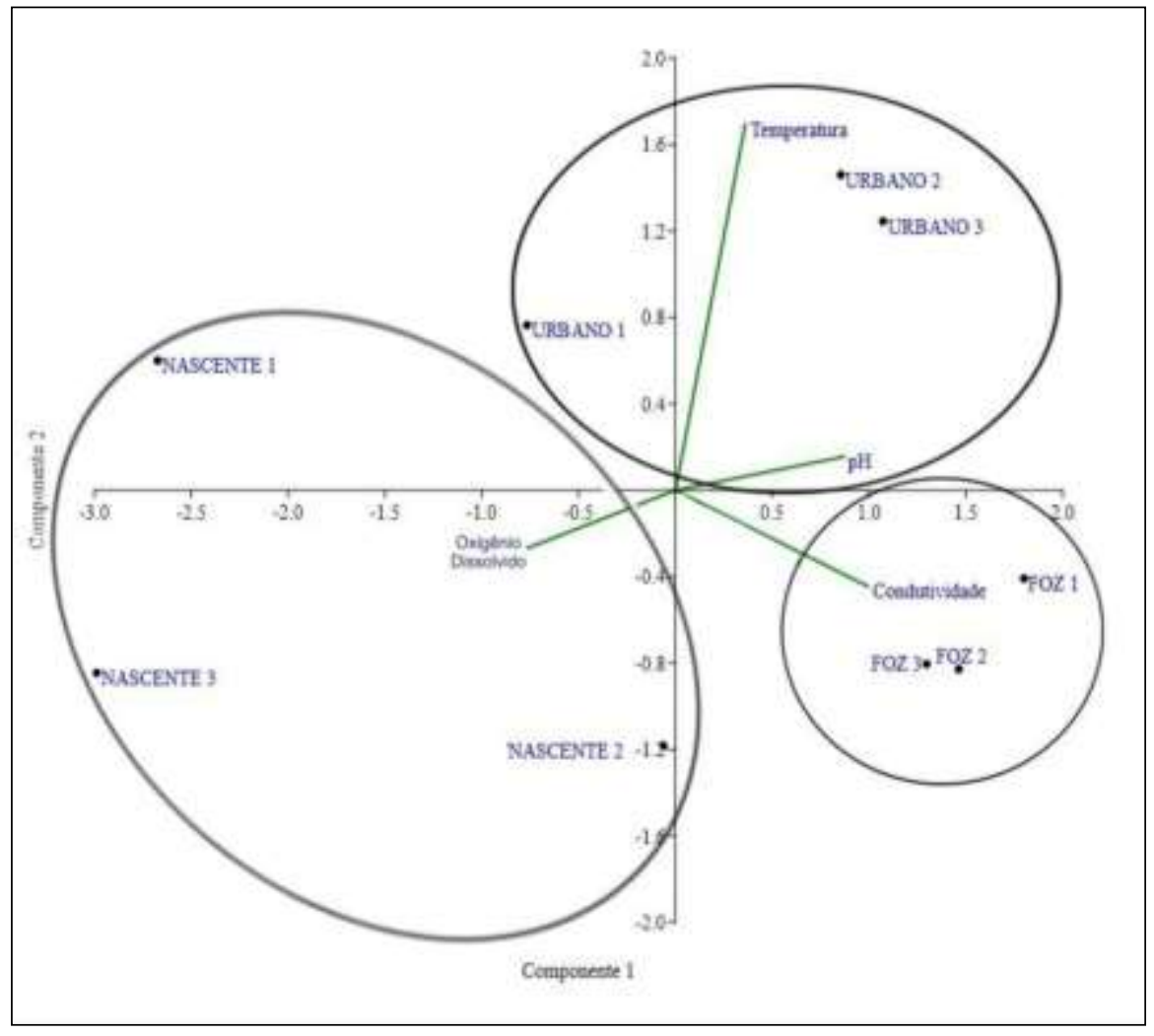

Fonte: Autores (2021).

Também, observou-se mediante a Análise de Variância que os fatores físico-químicos apresentaram valores significativamente distintos entre os pontos de amostragens da Nascente, Urbano e Foz, com valores de p < 0,001, para todas as variáveis analisadas (Figura 4). Onde a Temperatura e o $\mathrm{pH}$ apresentaram comportamentos semelhantes quando considerado o percurso do rio Ouricuri como um todo e a Condutividade elétrica e o Oxigênio dissolvido apresentam comportamento inverso, ou seja, enquanto a condutividade elétrica aumentou, o teor de Oxigênio dissolvido decresceu. 
Figura 4: Variação dos valores entre os parâmetros físico-químicos, (A) Temperatura, (B) Oxigênio Dissolvido, (C) pH e (D) Condutividade elétrica nos ambientes (Nascente, Urbano e Foz), no Rio Ouricuri, Capanema, Pará.

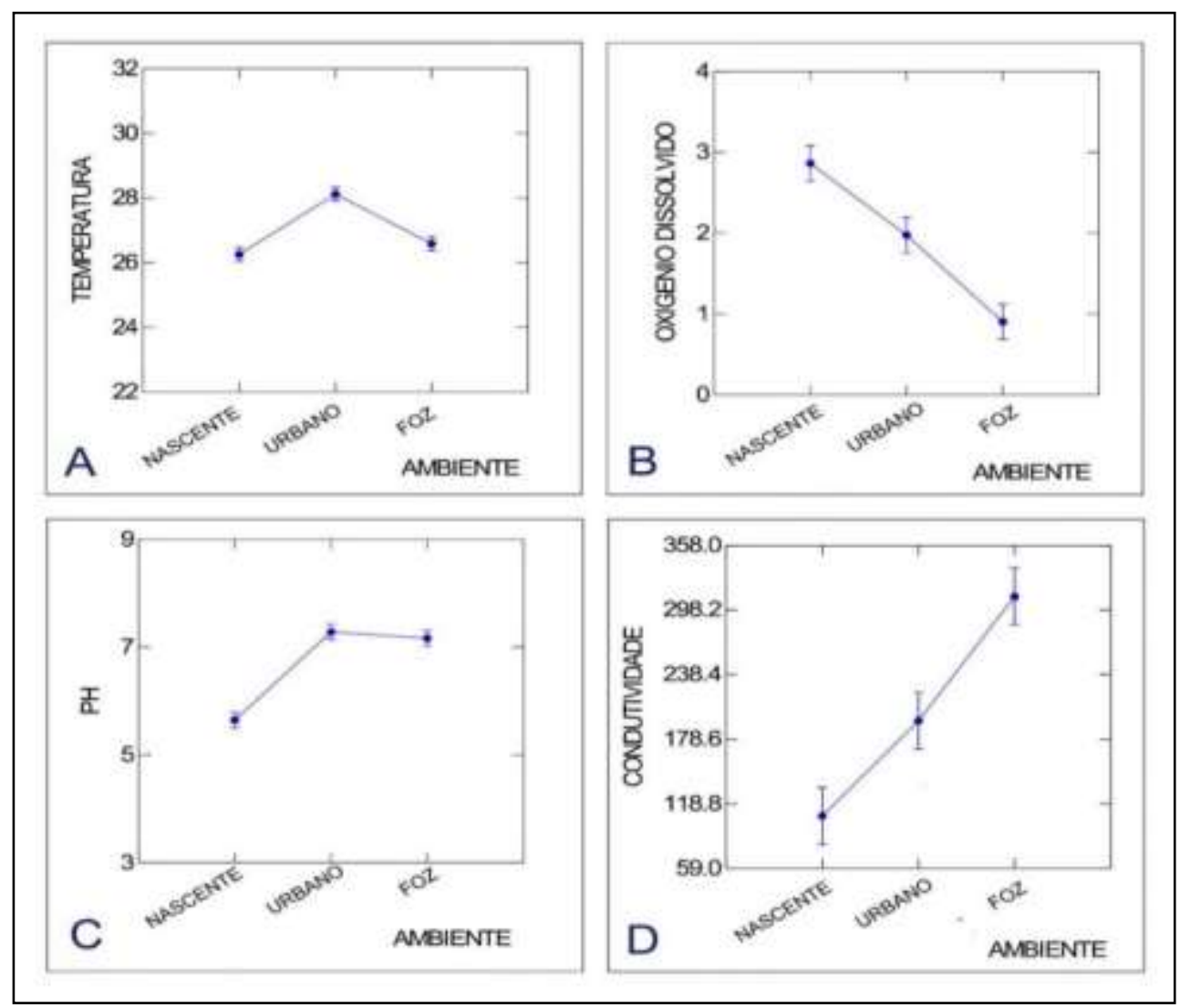

Fonte: Autores (2021).

A seguir serão expostos os valores de Temperatura, Oxigênio Dissolvido, pH e Condutividade elétrica, considerando suas variações sazonais nos ambientes amostrados.

\section{Temperatura}

As maiores médias $\left(28,12^{\circ} \mathrm{C} ; \pm 0,76\right)$ para a temperatura foram mensuradas na área urbana $(\mathrm{p}<0,001)$, na EC os pontos 2 e 3 no perímetro urbano apresentaram temperatura de $29,26{ }^{\circ} \mathrm{C}$ e $29,08{ }^{\circ} \mathrm{C}$ respectivamente, assim o parâmetro apresentou valores acima da média descrita para a região $\left(26^{\circ} \mathrm{C}\right)$, no entanto este não atingiu a temperatura máxima $\left(31^{\circ} \mathrm{C}\right)$, a supressão da vegetação ciliar em função da ocupação das margens devido o crescimento urbano desordenado, a remoção do banco de macrófitas com a proximidade da estação chuvosa, e a mudança na configuração do rio, tornando-o mais retilíneo e com menor profundidade, são fatores que podem ter influenciado a variação da temperatura (Tabela 1; Figura 5). 
Tabela 1: Valores da Temperatura para as estações menos chuvosa e chuvosa com a média geral para os períodos.

\begin{tabular}{l|ccc}
\hline \multirow{2}{*}{\multicolumn{1}{c|}{ AMBIENTE }} & \multicolumn{3}{c}{ TEMPERATURA ${ }^{\mathbf{0}}$ C (VALORES MÉDIOS) } \\
\cline { 2 - 4 } NASCENTE 1 & CHUVOSO & MENOS & GERAL \\
NASCENTE 2 & 25.60 & 28.20 & 26.90 \\
NASCENTE 3 & 27.01 & 25.24 & 26.12 \\
\hline Desvio Padrão & 25.56 & 25.90 & 25.73 \\
Média (Mínimo - & \pm 0.69 & \pm 1.29 & \pm 1.05 \\
\hline URBANO 1 & $26.06(25.28-27.22)$ & $26.45(25.17-$ & $26.25(25.17-$ \\
URBANO 2 & 27.34 & 27.50 & 27.42 \\
URBANO 3 & 29.26 & 27.81 & 28.54 \\
\hline Desvio Padrão & 29.08 & 27.72 & 28.40 \\
Média (Mínimo - & \pm 0.87 & \pm 0.14 & \pm 0.76 \\
\hline FOZ 1 & $28.56(27.33-29.33)$ & $27.68(27.43-27.89)$ & $28.12(27.33-$ \\
FOZ 2 & 26.78 & 27.19 & 26.99 \\
FOZ 3 & 26.24 & 26.61 & 26.42 \\
\hline Desvio Padrão & 25.21 & 27.47 & 26.34 \\
Média (Mínimo - & $26.07(24.54-26.81)$ & $27.09(26.49-$ & $26.58(24.54-$ \\
\hline
\end{tabular}

Fonte: Autores (2021).

O estudo realizado por Araújo et al. (2018), na represa Billings em São Paulo, constatou que áreas mais abertas, sem vegetação ciliar, propiciam a maior incidência de radiação solar e consequente aumento da temperatura. Menezes et al., (2016) verificaram em locais que recebem despejos orgânicos decorrentes de esgoto sanitário a tendência de elevação da temperatura e que o aumento do canal de rios ao longo do seu percurso provoca maior exposição à radiação solar e, consequentemente, aumento da temperatura da água.

Analisando as diferenças por ponto, entre as estações menos chuvosa e chuvosa, o ponto N1, foi o que apresentou a maior variação de temperatura $28,20^{\circ} \mathrm{Ce} 25,60^{\circ} \mathrm{C}$ (Figura 5; Tabela 1). Para Ribeiro, Mascarenhas e Silva, (2020), a temperatu ra da água influência nos processos de solubilidade dos gases aumentando ou diminuindo a taxa de dissolução, consumo e aspectos biológicos dos organismos aquáticos. De acordo com Bortoli et al., (2017) a temperatura influencia no crescimento de determinados organismos aquáticos, estes possuem limites de tolerância térmica.

Deste modo para Marmontel e Rodrigues, (2015), a presença da mata ciliar como barreira física é a maneira mais efetiva de prevenir aumentos da temperatura da água, oferecendo proteção, ao curso hídrico e as comunidades aquáticas, devido à menor exposição dos canais fluviais à luz solar, e serve como filtro natural para os lançamentos de efluentes, aumentando o tempo que estes levariam para chegar ao manancial. Na Figura 5 pode ser observado a variação de temperatura para as estações menos chuvosa e chuvosa de acordo com cada ponto de amostragem. 
Figura 5: Médias das temperaturas mensuradas nos pontos de coleta para as estações mais e menos chuvosa, com a linha média da temperatura anual para o município.

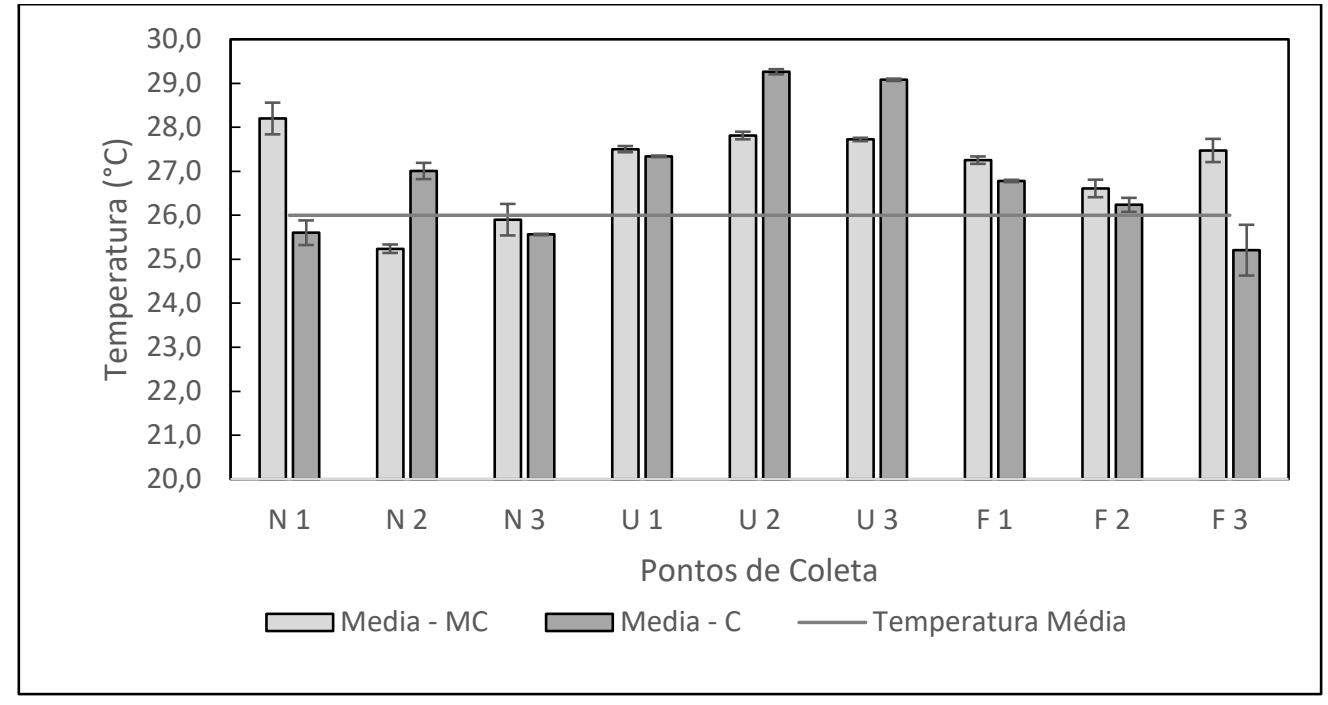

Fonte: Autores (2021).

\section{Potencial hidrogeniônico}

$\mathrm{O}$ pH apresentou valores médios mais baixos no ponto N1 com 4,91 e 4,27 nas estações menos chuvosa e chuvosa (Tabela 2; Figura 6), valores que estavam em desconformidade com a norma 357/2005 do CONAMA, que preconiza o valor de $\mathrm{pH}=6$ para águas naturais de classe 2 , este comportamente pode ser justificado devido a presença de matéria orgânica em decomposição oriunda da vegetação circundante, associado ao carater lêntico do ambiente. Silva et al., (2013) justificam que para a bacia amazônica os valores de pH podem ser mais ácidos devido as caracteristicas do solo e relaciona ainda a acidez elevada da água, à presença de ácidos orgânicos (ácidos húmicos e fúlvicos) proveniente da decomposição da vegetação.

Tabela 2: Valores de $\mathrm{pH}$ para as estações menos chuvosa e chuvosa com a média geral para os períodos.

\begin{tabular}{l|ccc}
\hline \multirow{2}{*}{ AMBIENTE } & \multicolumn{3}{c}{ POTENCIAL HIDROGENIÔNICO (VALORES MÉDIOS) } \\
\cline { 2 - 4 } & CHUVOSO & MENOS & GERAL \\
\hline NASCENTE 1 & 4.27 & 4.91 & 4.59 \\
NASCENTE 2 & 6.13 & 7.26 & 6.70 \\
NASCENTE 3 & 6.12 & 5.21 & 5.66 \\
\hline Desvio Padrão & \pm 0.89 & \pm 1.29 & \pm 0.99 \\
Média (Mínimo - Máximo) & $5.51(3.97-6.22)$ & $5.79(4.70-7.29)$ & $5.65(3.97-7.29)$ \\
\hline URBANO 1 & 7.07 & 7.64 & 7.35 \\
URBANO 2 & 7.01 & 7.47 & 7.24 \\
URBANO 3 & 7.21 & 7.30 & 7.26 \\
\hline Desvio Padrão & \pm 0.17 & \pm 0.14 & \pm 0.25 \\
Média (Mínimo - Máximo) & $7.09(6.69-7.24)$ & $7.47(7.18-7.24)$ & $7.28(6.69-7.75)$ \\
\hline FOZ 1 & 7.24 & 7.13 & 7.18 \\
FOZ 2 & 7.20 & 7.11 & 7.15 \\
FOZ 3 & 7.32 & 7.00 & 7.16 \\
\hline Desvio Padrão & \pm 0.10 & \pm 0.08 & \pm 0.13 \\
Média (Mínimo - Máximo) & $7.25(7.08-7.40)$ & $7.08(6.93-7.17)$ & $7.17(6.93-7.40)$ \\
\hline
\end{tabular}

Fonte: Autores (2021). 
O ponto N3 na área da nascente apresentou valores médios baixos para este parâmetro, 5,21 e 6,12 (Figura 6; Tabela 2), no entanto, apenas na estação menos chuvosa o valor estava abaixo da normativa, esta condição pode ser explicada pelo baixo nível da água devido o menor volume de chuvas, que assim concentra os ácidos oriundos da decomposição da vegetação, os demais pontos estavam dentro do padrão estabelecido para águas doces de classe 2.

Apesar das áreas ubana e foz recebem descargas de esgoto junto a drenagem pluvial urbana, Lopes e Magalhães Jr (2010) observaram em microbacias no estado de Minas Gerais ao, que o aporte de matéria orgânica proveniente de efluentes domésticos não tornam as águas da microbacia mais ácidas, e que a incidência de luz no corpo hídrico pode influenciar a variação do $\mathrm{pH}$ no decorrer do dia, favorecendo a fotossintese e a dissolução de gases em ambientes aquaticos. Na Figura 6, pode ser observado os valores de $\mathrm{pH}$ para cada ponto de coleta conforme a sazonalidade local, com os limites minimo e máximo estabelecido na legislação.

Figura 6: Valores de pH nos pontos de coleta nas estações menos chuvosa e chuvosa.

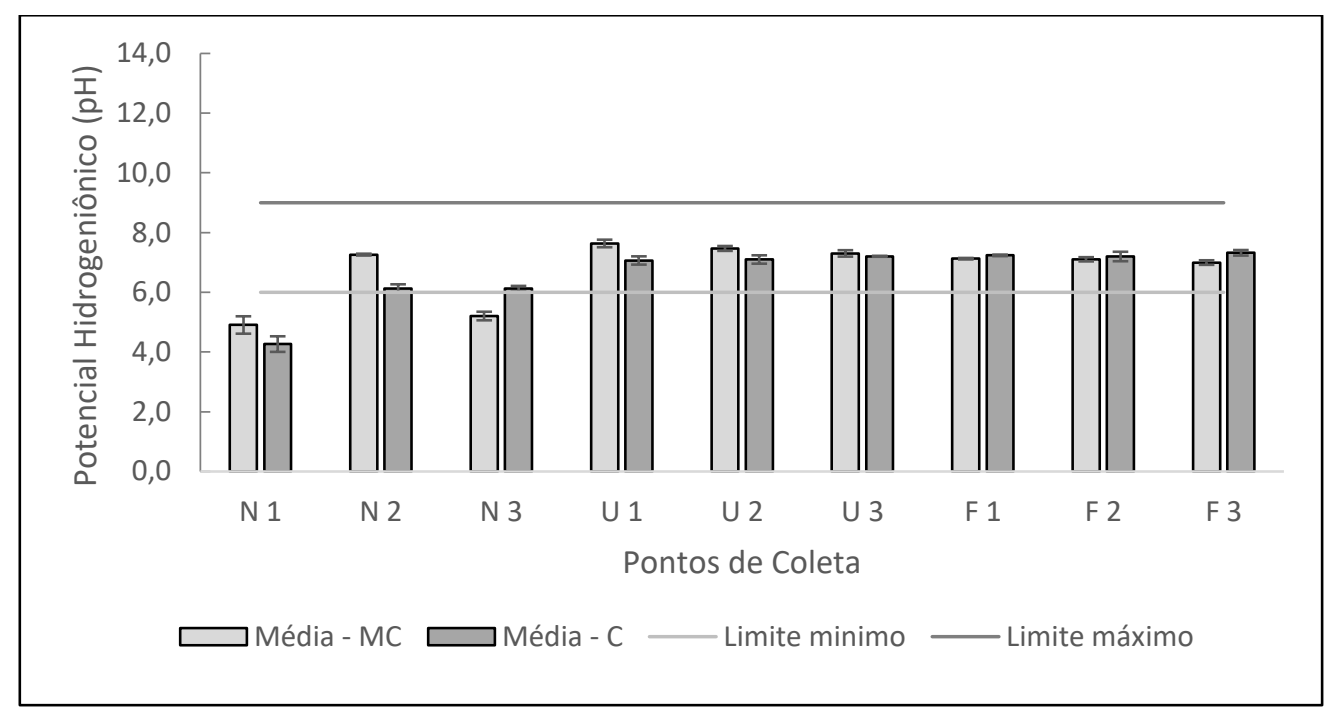

Fonte: Autores (2021).

\section{Oxigênio dissolvido}

O OD apresentou valores médios mais elevados na área da nascente, e um decréscimo do valor nos pontos das demais áreas ( $\mathrm{p}<0,001$ ), o ponto N3 se destacou com concentrações de 3,10 mg/l para a estação menos chuvosa e 4,92 mg/l para a estação chuvosa, o ponto 2 da nascente também apresentou valor elevado de OD, mas apenas na estação chuvosa (N2 = 3,89 mg/l) observou-se, que apesar da nascente apresentar valores maiores de OD (Figura 7; Tabela 3), este parâmetro está fora do estabelecido na legislação, onde, conforme a resolução 357/2005 do CONAMA, em águas doce, classe 2 o valor mínimo aceitável para OD é de $5 \mathrm{mg} / \mathrm{l}$.

Os valores obtidos neste estudo, corroboram com os encontrados por Costa et al., (2021) que avaliaram a bacia do rio Ouricurí, encontraram o valor médio de OD (4,87 mg/l) (Tabela 3; Figura 7), estando este também em desacordo com a normativa vigente. 
Tabela 3: Valores de Oxigênio Dissolvido para as estações menos chuvosa e chuvosa com a média geral para os períodos.

\begin{tabular}{l|ccc}
\hline \multirow{2}{*}{ AMBIENTE } & \multicolumn{3}{c}{ OXIGÊNIO DISSOLVIDO (VALORES MÉDIOS) } \\
\cline { 2 - 4 } & CHUVOSO & MENOS & GERAL \\
\hline NASCENTE 1 & 1.16 & 2.14 & 1.65 \\
NASCENTE 2 & 3.89 & 1.97 & 2.93 \\
NASCENTE 3 & 4.92 & 3.10 & 4.01 \\
\hline Desvio Padrão & \pm 1.62 & \pm 0.88 & \pm 1.38 \\
Média (Mínimo - Máximo) & $3.32(0.66-5.35)$ & $2.40(0.66-3.60)$ & $2.86(0.66-5.35)$ \\
\hline URBANO 1 & 2.55 & 2.99 & 2.77 \\
URBANO 2 & 1.48 & 1.76 & 1.62 \\
URBANO 3 & 1.22 & 1.83 & 1.53 \\
\hline Desvio Padrão & \pm 0.58 & \pm 0.69 & \pm 0.68 \\
Média (Mínimo - Máximo) & $2.20(1.21-2.64)$ & $1.75(1.36-3.11)$ & $1.97(1.21-3.11)$ \\
\hline FOZ 1 & 1.20 & 0.72 & 0.96 \\
FOZ 2 & 1.16 & 0.66 & 0.91 \\
FOZ 3 & 1.03 & 0.64 & 0.84 \\
\hline Desvio Padrão & \pm 0.08 & \pm 0.05 & \pm 0.24 \\
Média (Mínimo - Máximo) & $1.13(0.95-1.22)$ & $0.67(0.64-0.78)$ & $0.90(0.64-1.22)$ \\
\hline
\end{tabular}

Fonte: Autores (2021).

Gomes et al., (2019) ao estudarem a área de inundação da reserva extrativista Lago de Cuniã em Rondônia, observaram que a temperatura e a presença de matéria orgânica em decomposição influenciam na dissolução e aumentam o consumo de oxigênio, os autores afirmam que águas tropicais, especialmente as de área de várzea apresentam baixas taxas de dissolução de oxigênio em camadas próximo ao leito. Silva et al., (2018) atribuíram os baixos teores de OD em águas sob a influência das formações geológicas presentes no Nordeste Paraense a decomposição da matéria orgânica e a respiração de organismos. Os valores médios mensurados em cada ponto podem ser observados na Figura 7.

Figura 7: Distribuição das concentrações medias de OD por ponto de coleta, seguindo o fluxo do rio Ouricurí e nível mínimo de concentração estabelecido pela Resolução Conama 357/2005.

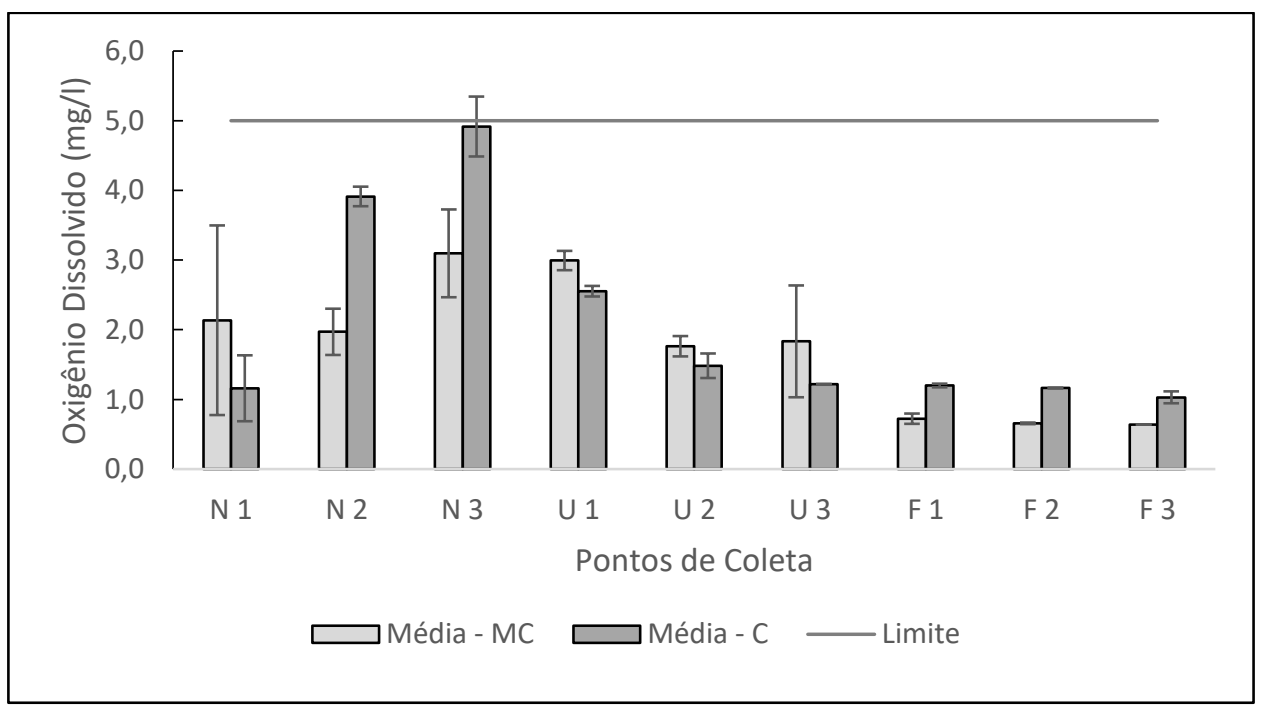

Fonte: Autores (2021). 


\section{Condutividade elétrica}

Os menores níveis de CE foram encontrados na área da nascente $(\mathrm{p}<0,001)$, tendo apenas o ponto N2 na estação menos chuvosa apresentado um valor elevado (N2 = 464.33), diferindo da condição dos demais pontos na área (Tabela 4; Figura 8), o ambiente no entorno de N2 possuía vegetação rasteira que estava se recuperando de uma queimada recente, o caráter lêntico e o baixo nível de água pode ter influenciado na concentração de íons que elevaram o valor de CE para a estação menos chuvosa no ponto em questão. Explicando essa condição, Machado, Granda e Endara, (2018), afirmam que a evaporação da água doce concentra os ions e sais presentes, assim elevando os níveis de condutividade.

Os valores de CE no rio Ouricurí aumentaram conforme a proximidade com a área urbana, alcançando os valores mais elevados na área da foz, apresentando maior valor médio no ponto $\mathrm{F} 1\left(\mathrm{~F} 1=403,00 \mu \mathrm{S} . \mathrm{cm}^{-1}\right)$ na estação menos chuvosa, seguido de U3 na estação chuvosa (U3 = 298,00 $\left.\mu \mathrm{S} . \mathrm{cm}^{-1}\right)$ (Figuras 4D e 8; Tabela 4). O Ministério da Saúde, estabelece que águas naturais não contaminadas por esgoto ou outra fonte poluidora de origem antrópica apresenta condutividade elétrica entre 10 $\mu \mathrm{S} . \mathrm{cm}^{-1}$ e $100 \mu \mathrm{S} . \mathrm{cm}^{-1}$ e águas poluídas podem apresentar valores de CE de até $1000 \mu \mathrm{S} . \mathrm{cm}^{-1}$ (Brasil, 2006).

Tabela 4: Valores da Condutividade Elétrica para as estações menos chuvosa e chuvosa com a média geral para os períodos.

\begin{tabular}{l|ccc}
\hline \multirow{2}{*}{ AMBIENTE } & \multicolumn{3}{c}{ CONDUTIVIDADE (VALORES MÉDIOS) } \\
\cline { 2 - 4 } & CHUVOSO & MENOS & GERAL \\
\hline NASCENTE 1 & 25.33 & 12.67 & 19.00 \\
NASCENTE 2 & 47.67 & 464.33 & 256.00 \\
NASCENTE 3 & 77.67 & 18.00 & 47.83 \\
\hline Desvio Padrão & \pm 23.06 & \pm 211.79 & \pm 161.21 \\
Média (Mínimo - Máximo) & $50.22(12-78)$ & $165.00(10-475)$ & $107.61(10-475)$ \\
\hline URBANO 1 & 82.00 & 139.67 & 110.83 \\
URBANO 2 & 286.33 & 167.00 & 226.67 \\
URBANO 3 & 298.33 & 200.67 & 249.50 \\
\hline Desvio Padrão & \pm 99.43 & \pm 25.24 & \pm 77.24 \\
Média (Mínimo - Máximo) & $222.22(80-305)$ & $169.11(136-203)$ & $195.67(80-305)$ \\
\hline FOZ 1 & 268.33 & 403.00 & 335.67 \\
FOZ 2 & 255.00 & 359.67 & 307.33 \\
FOZ 3 & 251.00 & 327.00 & 289.00 \\
\hline Desvio Padrão & \pm 7.59 & \pm 32.53 & \pm 57.62 \\
Média (Mínimo - Máximo) & $258.11(249-270)$ & $363.22(310-412)$ & $310.67(249-$ \\
\hline
\end{tabular}

Fonte: Autores (2021).

Pereira et al., (2016), ao estudarem a qualidade da água da bacia do rio Peixe-boi, no Nordeste Paraense, constataram que quanto mais próximo as áreas urbanas, a condutividade elétrica apresentava valores mais elevados, pois esta reflete a presença de sais dissolvidos na água na forma de íons dissociados eletroliticamente, quando de origem antrópica esses íons são resultantes de esgotos domésticos e descargas industriais oriundas da drenagem urbana. Menezes et al., (2016) denominam este comportamento como "síndrome dos rios Urbanos". Schiller et al., (2017), evidenciam que valores elevados de CE são um indicio importante de possível poluição, mas que não discrimina os íons presentes na água. 
Figura 8: Níveis de condutividade elétrica nos pontos de coleta no rio Ouricurí e nível máximo estabelecido para águas naturais pelo Ministério da Saúde

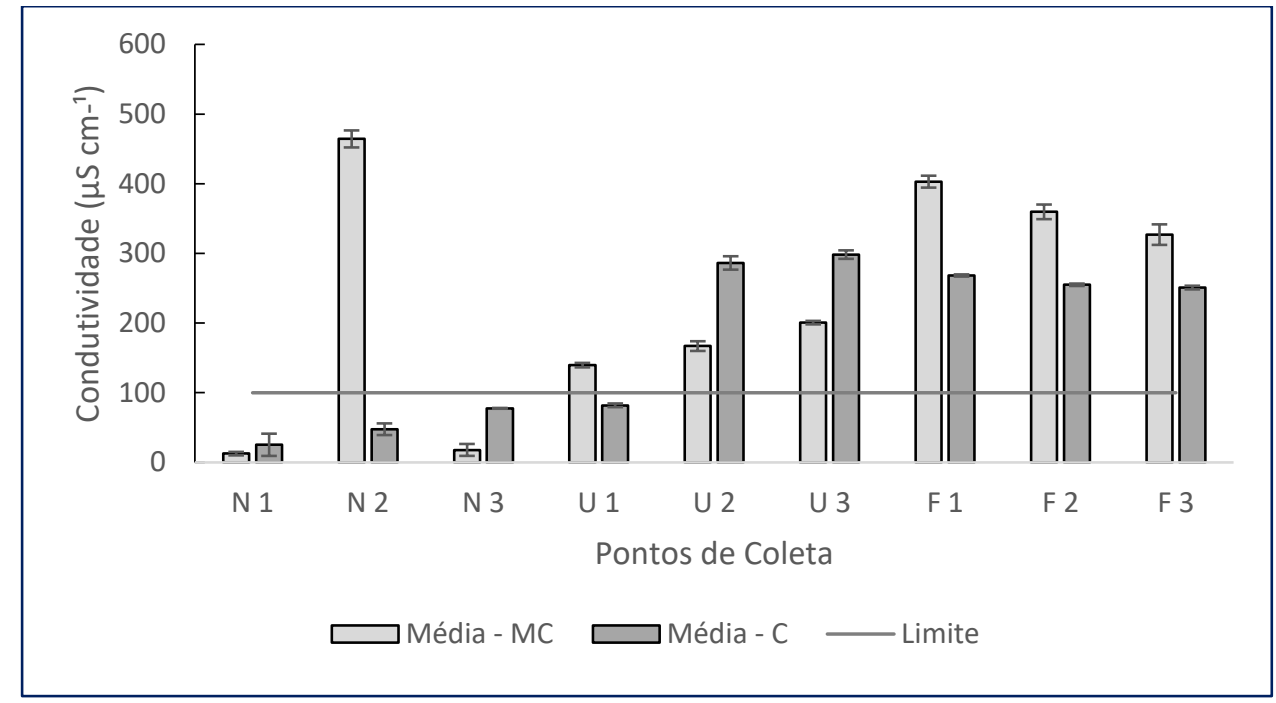

Fonte: Autores (2021).

Gardiman Junior (2015), ao avaliar a bacia hidrográfica do rio Jucu no estado do Espirito Santo discorre que em ambientes aquáticos de regiões tropicais, a condutividade elétrica relaciona-se mais à composição geoquímica e as condições de seca e chuva, explica ainda que a condutividade da água aumenta à medida que mais sólidos dissolvidos são adicionados. Na Figura 8, pode ser observado a variação de CE nos pontos de Coleta, seguindo o curso do rio Ouricurí, considerando a sazonalidade local e o valor estabelecido na legislação.

\section{Considerações Finais}

Este estudo evidencia que o crescimento urbano desordenado influencia negativamente nas condições físicas-químicas do rio Ouricurí, em Capanema, Pará, pois modifica a vegetação ciliar e o curso do rio, causa assoreamento, drena efluentes gerados na cidade para o rio, aumenta o número de resíduos sólidos no rio e com isso leva a mudanças nos parâmetros físicoquímicos indicativos da qualidade da água.

Quando comparados aos valores obtidos no estudo com a legislação, observou-se que a área da nascente se encontra em melhor condição, apresentando valores baixos de condutividade, dentro do estipulado pelo ministério da saúde para águas naturais, e apesar de os valores para oxigênio dissolvido e pH estarem foram dos padrões exigidos pela Resolução Conama $357 / 2005$ para águas naturais de classe 2, isso pode ser reflexo da condição natural dos solos e do ambiente circundante, mas que ao alcançar o meio urbano essa condição é modificada no rio.

A sazonalidade local e o incremento das chuvas também geram mudanças nas características do rio, faz com que o nível da água se eleve, lixiviando material para o recurso hídrico, solubilizando e dissolvendo poluentes, aumentando o teor de oxigênio dissolvido em alguns pontos e devido a correnteza pode causar o arrasto de material depositado no leito do rio que serve de microhabitats e alimento para a micro e macrobiota.

Constatou-se que a preservação da vegetação é um ponto importante a ser considerado, pois esta serve como uma barreira para a entrada de poluentes e resíduos sólidos, os pontos que apresentaram a vegetação em melhor estado de conservação também obtiveram melhores valores para os parâmetros físico-químicos.

Estudos como este são importantes para a tomada de decisões dentro do município, e para a promoção de políticas de conservação do ambiente, pois a partir destes são identificados os pontos ou áreas que necessitam de intervenção, possibilitando a produção de novos trabalhos que por exemplo identifique quais as principais fontes de contaminação e degradação dos corpos 
hídricos, onde estas se concentram e como modificam o espaço urbano. Assim podendo atuar na educação e sensibilização da população local a respeito das boas práticas de descarte de efluentes e resíduos sólidos, ocupação e uso do espaço que podem levar a deterioração da qualidade ambiental de rios.

\section{Referências}

Andrade, F. S., Silva, A. M., Aride, P. H. R. \& Oliveira, A. T. (2016). Análise físico-química e da microbiota da água do lago Macurany, Parintins, Amazonas. Biota Amazônia, Macapá, 6, n2. p. 132-134, 2016. DOI: http://dx.doi.org/10.18561/2179-5746/biotaamazonia.v6n2p132-134.

Araújo, P. L., Hamburger, D. S., Jesus, T. A., Benassi, R. F. \& Cicco, V. (2018). Relação entre a qualidade da água e o uso do solo em microbacias do reservatório Billings, na Região Metropolitana de São Paulo - SP. Revista de Gestão de Água da América Latina, Porto Alegre, 15 , e2.

Brasil. (2005). Ministério do Meio Ambiente. Resolução CONAMA no 357 de 17 de março de 2005. Dispõe sobre a classificação dos corpos de água e diretrizes ambientais para o seu enquadramento, bem como estabelece as condições e padrões de lançamento de efluentes, e dá outras providências. http://www2.mma.gov.br/port/conama/res/res05/res35705.pdf.

Brasil. (2005). Ministério da Saúde. Secretaria de Vigilância em Saúde. Vigilância e controle da qualidade da água para consumo humano/ Ministério da Saúde, Secretaria de Vigilância em Saúde. - Brasília: Ministério da Saúde, 2006. 212 p. - (Série B. Textos Básicos de Saúde) ISBN 85-334-1240-1

Ceolin, L. P. W., Aguiar Júnior, T. R. \& Morais, M. M. (2017). Avaliação de impactos ambientais em sistemas aquáticos. Caso de estudo do Rio Órbigo, Espanha. Revista Brasileira de Geografia Física, 10, n2. pag. 535-542.

Couceiro, S.R.M. (2009). Sedimentos antropogênicos em igarapés da base de operações geólogo Pedro Moura: efeito sobre macroinvertebrados e degradação de folhas. (Tese de Doutorado) Programa de Pós-graduação em Ecologia. Brasília. Distrito Federal.

Costa, A. R. S., Aragão, R. M., Sousa Junior, P. M., Alves, M. H. D.; Gonçalves, A. C. S., Teixeira, O. M. M.; Monteiro, G. C. \& Faial, K. C. F. (2021). Impacto da urbanização nas águas superficiais de uma microbacia urbana no município de Capanema/PA, Brasil. Revista Ibero Americana de Ciências Ambientais, v.12, n.2, p.203-215. DOI: http://doi.org/10.6008/CBPC2179-6858.2021.002.0020

Fapespa - Fundação Amazônia De Amparo A Estudos E Pesquisas. (2016). Estatísticas Municipais Paraenses: Capanema. / Diretoria de Estatística e de Tecnologia e Gestão da Informação. - Belém, 2016.

Ferreira, D. A.T., Monteiro, E. C., Duarte, J. A. S., Monteiro, M. Silva, M. S. A. \& Souza, J. M. (2014). Grau de Degradação de Dois Córregos Urbanos no Município de Alta Floresta- MT: Variáveis Físico-Químicas. Enciclopédia Biosfera, Centro Científico Conhecer - Goiânia, 10 , n18; p.1896.

Gardiman Junior, B. S. (2015). Caracterização do processo de poluição das águas superficiais da Bacia Hidrográfica do Rio Jucu, estado do Espírito Santo, Brasil. Revista Agro@mbiente, 9, n3, p. 235-242. DOI:10.18227/1982-8470ragro.v9i3.2310. ISSN 1982-8470

Gomes, D. F., Sanches, N. A. O., Andrade, D. P. \& Bastos, W. R. (2019). Ccurrence of Aquatic Macroinvertebrates in an Extrativist Reserve of Brazilian Amazon. Revista Biologia Neotropical. / J. Neotrop. Biol., Goiânia, 16, n2, p. 5060, jul.dez. ISSN - 1807-9652.

Lima, S. M. S. A., Lopes, W. G. R. \& Façanha, A. C. (2019). Desafios do planejamento urbano na expansão das cidades: entre planos e realidade. urbe. Revista Brasileira de Gestão Urbana, 11, e20190037. https://doi.org/10.1590/2175-3369.011.e20180037

Lopes, F. W. A. \& Magalhães Jr, A. P. (2010). Influência das condições naturais de pH sobre o índice de qualidade das águas (IQA) na bacia do Ribeirão de Carrancas. Revista Brasileira de Recursos Hídricos (RBRH)O. DOI: https://doi.org/10.35699/2237-549X\%20.13301

Machado, V., Granda, R. \& Endara, A. (2018). Análisis de macroinvertebrados bentónicos e índices biológicos para evaluar la calidad del agua del Río Sardinas, Chocó Andino Ecuatoriano. Enfoque UTE, 9, n4, p. 154 - 167. p-ISSN: 1390-9363

Pereira, B. W. F., Maciel, M. N. M., Oliveira, F. A. Alves, M, A. M. S., Ribeiro, A. M., Ferreira, B. M. \& Ribeiro, E. G. P. (2016). Uso da terra e degradação na qualidade da água na bacia hidrográfica do rio Peixe-Boi, PA, Brasil. Revista Ambiente e Água. 11, n2. ISSN 1980-993X - doi:10.4136/1980-993X

Pereira, M. C. S., Martins, J. R. S., Nogueira, F. F., Magalhães, A. A. B. \& Silva, F. P. (2021). Melhoria da qualidade da água de rios urbanos: novos paradigmas a explorar - Bacia hidrográfica do rio Pinheiros em São Paulo. Engenharia Sanititaria e Ambiental. 26, n3. p. 577-590. https://doi.org/10.1590/S1413415220190272

Ribeiro, J. M. F., Mascarenhas, B. M. \& Silva, P. L. F. (2020). Insetos aquáticos da bacia hidrográfica do rio peixe-boi, nordeste paraense. In: Ciências ambientais: fauna e flora da Amazônia / Altem Nascimento Pontes; Alessandro Silva do Rosário (Orgs.). EDUEPA. ISBN 978-65-88106-07-5.

Ribeiro, W. O. (2019). Situação espacial, interações e centralidade: a condição de capanema na rede urbana do nordeste paraense. in: Amazônia: fronteiras, grandes projetos e movimentos sociais / Organização de Aiala Colares de Oliveira Couto, Tiago Veloso dos Santos, Wilame de Oliveira Ribeiro. EDUEPA. ISBN 978-85-8458-042-2.

Silva, E. R. M., Costa, L. G. S., Silva, A. S., Souza, E. C. \& Barbosa, I. C. C. (2018). Caracterização Físico-Química, Química e Quimiométrica de Águas Subterrâneas dos Aquíferos Pirabas e Barreiras em Municípios do Estado do Pará. Revista Brasileira de Geografia Física. 11, n3. ISSN: $1984-2295$.

Silva, M. S. R., Miranda, S. Á. F., Domingos, R. N., Silva, S. L. R., \& Santana, G. P. (2013). Classificação dos Rios da Amazônia: Uma Estratégia Para Preservação Desses Recursos. HOLOS Environment. 13, n2. P. 163. ISSN:1519-8634.

Silva K.W.S., Ewerton, N. S \& Melo, S, A, D. (2016). Aplicação dos índices biológicos BMWP e ASPT para avaliar a qualidade de água do rio Ouricuri. Revista Pan-Amazonica de Saúde 2016; 7(3):13-22. DOI: 10.5123/S2176-62232016000300002 
Research, Society and Development, v. 10, n. 16, e51101622866, 2021

(CC BY 4.0) | ISSN 2525-3409 | DOI: http://dx.doi.org/10.33448/rsd-v10i16.22866

Menezes, J. P. C., Bittencourt, R. P., Farias, M. S., Bello, I. P., Fia, R. \& Oliveira, L. F. C. (2016). Relação entre padrões de uso e ocupação do solo e qualidade da água em uma bacia hidrográfica urbana. Engenharia Sanitaria e Ambiental. 21, n.3. p. 519-534. DOI: 10.1590/S1413-41522016145405.

Bortoli, J., Rempel, C., Maciel, M. J. \& Salvi, L. C. (2017). Qualidade Físico-Química da Água em Propriedades Rurais com Produção de Leite no Vale do Taquari-Rs. Caderno Prudentino de Geografia. 39, v.1, p. 81-102. ISSN: 2176-5774.

Marmontel, C. V. F. \& Rodrigues, V. A. (2015). Parâmetros Indicativos para Qualidade da Água em Nascentes com Diferentes Coberturas de Terra e Conservação da Vegetação Ciliar. Revista Floresta e Ambiente, 22, v2. p. 171-181. DOI: http://dx.doi.org/10.1590/2179-8087.082014. ISSN 2179-8087. 